\title{
Corrosion and mechanical behavior of ion implanted bearing steels for improved fretting behavior
}

\author{
G. S. Was

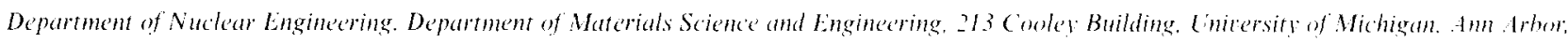 \\ $M I S 109($ USA)
}

\section{J. D. Demaree}

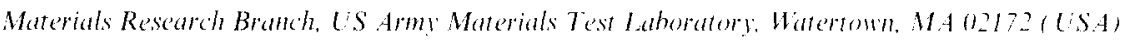

\section{Rotberg}

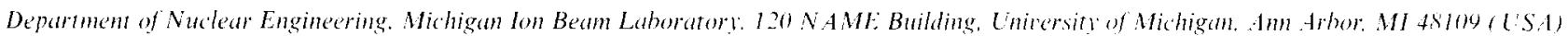

K. Kim

Department of Mechanical Engineering and Applied Medhanics, 3001 EECS. Cintersity of Michigan. Ann Arhor. MI 4Rl(1) (LSA)

\begin{abstract}
Ion implantation of AISI 52100 and 1070 steels was conducted in order to improve the corrosion. wear and ultimately the fretting behavior of the steels. Implantations consisted of $1 \times 10^{17} \mathrm{Tat}^{1} \mathrm{~cm}^{2} .3 \times 10^{17} \mathrm{Ti}^{3} \mathrm{~cm}^{2}+1.5 \times 10^{17} \mathrm{C}^{1} \mathrm{~cm}^{2}$. and $3.1 \times 10^{17} \mathrm{Ti}^{\circ} \mathrm{cm}^{2}+1.55 \times 10^{17} \mathrm{~N}^{+} \mathrm{cm}=$. All implantations were successful in improving the corrosion resistance. On averatge the peak anodic current was reduced by over $300 \mathrm{mV}$, the passivation potential was reduced, and the pitting potential was increased by over $1000 \mathrm{mV}$ in $0.01 \mathrm{M} \mathrm{NaCl}$. Ti $+\mathrm{C}$ and $\mathrm{Ti}+\mathrm{N}$ implantations increased the load-carrying capacity in lubricated scuffing tests by $60 \%$ and $40 \%$ respectively. Ta produced no improvement in scuffing resistance. Ti $+\mathrm{N}$ implantation increased the hardness by $25 \%$ over the unimplanted steel and both $\mathrm{T} i+\mathrm{C}$ and $\mathrm{Ta}$ implantation reduced the surface hardness. Fretting wear was reduced only slightly in the Ta implanted sample and increased in both the $\mathrm{Ti}+\mathrm{C}$ and $\mathrm{Ti}+\mathrm{N}$ implanted samples with the latter showing 45 times the weight loss as the unimplanted sample. The correlation between fretting and hardness supports a mechanism in which the hard surface layer breaks into fine particles which act as an abrasive under the intense load of the balls.
\end{abstract}

\section{Introduction}

It has been widely demonstrated that ion implantation can alter the mechanical properties and corrosion behavior of many alloys. Of particular importance are the bearing steels such as AISI M50 and 52100. Service application often requires the use of these steels in aggressive environments or under severe localized wear modes. Applications require selection of the proper implant to improve the property which is responsible for in-service degradation. Implantation of $\mathrm{Ti}$ and $\mathrm{C}$ or $\mathrm{Cr}$ and Mo into M50 steel are both successful, but for different reasons. The main benefit of implantation consisting of $\mathrm{Ti}$ and $\mathrm{C}$ is believed to be the reduction in the friction coefficient by the formation of an amorphous phase $[1,2]$. The decrease in friction under lubricated test conditions has been attributed to enhanced wetting characteristics of the interface which promotes hydrodynamic flow and inhibits surface contact [3]. The beneficial effect of a $\mathrm{Cr}$ and Mo implantation is due to a different reason. In a corrosive environment such as seawater, $\mathrm{Cr}$ imparts passivity to the bearing and $\mathrm{Mo}$ inhibits pitting of the passive film by the chloride ions [4].

Another severe wear process is fretting, or surface damage caused by low-amplitude oscillatory sliding between two contacting surfaces. Fretting is a complicated process involving the effect of contact conditions, environmental conditions and material properties [5]. Since fretting is intimately related to wear, corrosion and fatigue $[6,7]$, increasing the resistance to fretting is best accomplished by surface modifications which address these other degradation mechanisms. The problem at hand is the fretting of AISI 52100 and 1070 bearings by low amplitude oscillatory motion of the balls. Ion implantation is explored as a possible means of addressing this issue. Specifically, three implantation treatments have been selected: $\mathrm{Ta}, \mathrm{Ti}+\mathrm{C}$ and $\mathrm{Ti}+\mathrm{N}$ implantation into 52100 and 1070 steels. To date, very little work has been done to explore the potential role of implantation on fretting. Therefore, implantations are selected on the basis of their effectiveness in improving wear, fatigue and corrosion of bearing steels. $\mathrm{Ti}+\mathrm{C}$ has been shown to improve wear behavior, as previously 
mentioned. $\mathrm{Ti}+\mathrm{N}$ has been very successful in reducing wear and corrosion when applied as a surface coating. Finally, $\mathrm{Ta}$ is very effective in improving the corrosion behavior of steels. Since fatigue spalling is improved by a reduction in friction and the introduction of compressive stresses, all implantations are expected to contribute to mitigation of this degradation mode.

\section{Experiment}

\subsection{Materials}

The materials were supplied in three forms: corrosion coupons $16 \mathrm{~mm}(0.625 \mathrm{inch})$ in diameter by $3 \mathrm{~mm}(0.125$ inch) thick, wear disks $38 \mathrm{~mm}$ ( 1.5 inch) in diameter by $6 \mathrm{~mm}(0.25$ inch $)$ thick, and frettage test bearing races $35 \mathrm{~mm}$ ( 1.375 inch) in diameter by $4 \mathrm{~mm}(0.16$ inch $)$ thick. The corrosion and wear disks were made from both AISI $52100(\mathrm{Fe}-1.5 \mathrm{Cr}-1 \mathrm{C}-0.3 \mathrm{Mn}-0.2 \mathrm{Si})$ or 1070 ( $\mathrm{Fe}-(0.8-1.1) \mathrm{Mn}-0.7 \mathrm{C}-(0.1-0.15) \mathrm{Cr})$ steels in the hardened and tempered condition. The heat treatment consisted of a soak at $843^{\circ} \mathrm{C}\left(1550^{\circ} \mathrm{F}\right)$ for $45 \mathrm{~min}$ followed by an oil quench and a tempering treatment at $232^{\circ} \mathrm{C}$ $\left(450^{\circ} \mathrm{F}\right)$ for $1 \mathrm{~h}$. The resulting hardness of the samples was $R_{c} 59$. The bearing races were made out of 52100 only and were annular in shape with an inner diameter of $16 \mathrm{~mm}$, a thickness of $4 \mathrm{~mm}$, and a curved bearing raceway. Their hardness was $R_{c} 59$ as well. The corrosion and wear disks received a final mechanical polish consisting of $1 \mu \mathrm{m}$ diamond paste, and the bearing races were used in the as-received condition.

\subsection{Implantation}

Implantations were conducted on corrosion and wear disks of alloys 1070 and 52100 and on the curved bearing raceway of the alloy 52100 races. Implantations consisted of three types: $\mathrm{Ti}+\mathrm{C}$ which was $3 \times 10^{17} \mathrm{Ti}^{+} \mathrm{cm}^{-2}$ at $120 \mathrm{keV}$ followed by $1.5 \times 10^{17} \mathrm{C}^{+} \mathrm{cm}^{-2}$ at $40 \mathrm{keV}$, Ta which consisted of $1 \times 10^{17} \mathrm{Ta}^{+} \mathrm{cm}^{-2}$ at $140 \mathrm{keV}$, and $\mathrm{Ti}+\mathrm{N}$ which consisted of $3.1 \times 10^{17} \mathrm{Ti}^{+} \mathrm{cm}^{-2}$ at $180 \mathrm{keV}$ and $1.55 \times 10^{17} \mathrm{~N}_{2}^{+} \mathrm{cm}^{-2}$ at $120 \mathrm{keV}$ (assumed to be equivalent to $3.1 \times 10^{17} \mathrm{~N}^{+} \mathrm{cm}^{-2}$ at $60 \mathrm{keV}$ ). Ti+C and Ta implantations were conducted at SPIRE Corporation and the $\mathrm{T} i+\mathrm{N}$ implantation was performed at the Michigan Ion Beam Laboratory (MIBL) at the University of Michigan. Vacuums in both cases ranged from mid $10^{-6}$ to low $10^{-7}$ Torr. So as not to disturb the metallurgical microstructure by beam heating, beam currents were limited to $1 \mu \mathrm{A} \mathrm{cm}^{-2}$. In all cases, the beam was rastered across the sample at an angle normal to the plane of the sample. In the case of the bearing races, this resulted in a $0^{\circ}$ implantation angle only at the bottom of the bearing track, which is appropriate for the frettage test procedure. The energies of the $\mathrm{Ti}+\mathrm{C}$ and $\mathrm{Ti}+\mathrm{N}$ were chosen to result in coincidence of the peaks of the implanted profiles. The results of Hubler et al. [8] were used to guide the selection of dose for both implants. The energy of the Ta implantation was set at the maximum achievable and the dose was chosen based on corrosion results from Hubler et al. [8].

\subsection{Composition analysis}

The composition of the implanted surfaces was analyzed using Rutherford backscattering spectrometry (RBS) and X-ray photoelectron spectroscopy (XPS). RBS was performed using $2 \mathrm{MeV} \mathrm{He}^{2+}$ in the Tandetron accelerator at the MIBL. Analysis of the Ta implantation was straightforward since the mass of $\mathrm{Ta}$ is greater than that of the substrate. Analysis of the $\mathrm{Ti}+\mathrm{C}$ and $\mathrm{Ti}+\mathrm{N}$ implantations was aided by the use of the PROFILE code [9] to determine the composition profile of the implanted species. XPS was performed on a Perkin-Elmer PHI 5400 X-ray photoelectron spectrometer by surface depth profiling using $3 \mathrm{keV} \mathrm{Ar}^{+}$ions.

\subsection{Corrosion}

Potentiodynamic polarization scans were conducted in either $0.5 \mathrm{~N}$ sulfuric acid or $0.01 \mathrm{M} \mathrm{NaCl}$ in $\mathrm{pH} 6.0$ phosphate buffer on corrosion disks that were lacquered off to expose a small $\left(0.02-0.2 \mathrm{~cm}^{2}\right)$ area to the solution. Polarization scans were begun soon after immersion in the acid solution since reduction of the air-formed film occurred quickly at the open-circuit potential. However, the reduction of the film was much slower in the chloride solution. As such the sample was held at a potential $250 \mathrm{mV}$ below open-circuit for several minutes prior to performing polarization scans. Both solutions were deaerated prior to testing. Polarization scans were conducted at a rate of $1 \mathrm{mV} \mathrm{s}^{-1}$ and began at $-1000 \mathrm{mV}$ (SCE) in the chloride solution and at $-10 \mathrm{mV}$ (SCE) in the acid solution using a Princeton Applied Research (PAR) model 173 potentiostat with a model 276 digital interface linking it to an IBM personal computer.

\subsection{Wear and hardness}

The hardness of the unimplanted and implanted surfaces was measured using a Matsuzawa MXT70-UL Knoop hardness indenter with loads in the range 1-10 g. The wear behavior of the various surface treatments was determined by a scuffing test procedure. In this test, a stationary ball is pressed into contact with a rotating flat disk specimen. The contact load is determined by weights applied to the end of the bar to which the stationary slider is attached. The applied load can be controlled up to a maximum of $1300 \mathrm{~N}$. The ball, which is taken from a bearing, slides on a flat surface in a direction parallel to the disk surface at a speed of $0.72 \mathrm{~m}$ $\mathrm{s}^{-1}$, controlled with a d.c. servo motor. Mineral oil was used as lubricant. A conventional step loading method 
was used in which the applied load is increased after sliding for a fixed amount of time ( $5 \mathrm{~min}$ ) with a constant applied load. The coefficient of friction was measured as a function of load.

\subsection{Fretting}

Frettage tests were conducted in a Fafnir model 11636 friction oxidation tester which consists of a chuck containing two test bearings. Each bearing consists of a pair of bearing races and nine, $6 \mathrm{~mm}$ (0.25 inch) diameter balls made of AISI 52100. The test load is applied by tightening the castle nut until the calibrated coil spring is compressed to the step or shoulder on the chuck top shaft. When assembled, one race or washer of each of the two bearing sets mounted in the oscillating bearing seat is free to oscillate with respect to their fixed mates mounted in the chuck top and base. An eccentric mounted on the motor shaft and connected to the oscillating bearing seat crank by means of a connecting rod makes the small angle of oscillation possible.

Test bearing races were cleaned and weighed to the nearest $0.1 \mathrm{mg}$ before being assembled with the test grease (Esso Nebula EP1 Batch 2) and mounted in the test equipment. The bearings were then tested at a constant temperature of $-32^{\circ} \mathrm{C}\left(0^{\circ} \mathrm{F}\right)$, a frequency of $30 \mathrm{~Hz}$ and a force of $2446 \mathrm{~N}(550 \mathrm{lbs})$ for $22 \mathrm{~h}$. On removal, the races were again cleaned and weighed with the fretting wear determined by the weight loss experienced by the races.

\section{Results and discussion}

\subsection{Composition}

RBS spectra and composition profiles as determined by XPS for the three implantations are shown in Figs. 1-3. The RBS plots, Figs. 1(a)-3(a), show both the measured spectrum and the RUMP simulation giving the best fit. The simulation was based on composition vs. depth profiles determined using the ProfILE code, and adjusting the sputtering coefficient until the best fit was achieved. The retained dose is also shown for each implanted specie. Figures 1 (b)-3(b) show the results of XPS depth profiling using $3 \mathrm{keV} \mathrm{Ar}^{+}$at a current density of about $8 \mu \mathrm{A} \mathrm{cm} \mathrm{cm}^{-2}$ for $\mathrm{Ta}$ and $\mathrm{Ti}+\mathrm{C}$ and $80 \mu \mathrm{A} \mathrm{cm} \mathrm{cm}^{-2}$ for $\mathrm{T} i+\mathrm{N}$. A sputtering rate of $3 \AA \mathrm{min}^{-1}$ was assumed in the conversion from sputter time to depth for Ta and $\mathrm{Ti}+\mathrm{C}$ and $30 \AA \min ^{-1}$ for $\mathrm{Ti}+\mathrm{N}$.

RBS and XPS results both agree in the amount and distribution of $\mathrm{Ta}$. The retained $\mathrm{Ta}$ dose is $4.1 \times 10^{16} \mathrm{~cm}^{-2}$ or $41 \%$ of the nominal dose (which yields a sputtering coefficient for $\mathrm{Ta}$ of about 2.7) and it is distributed in the form of a truncated Gaussian distribution with a peak at about $7.5 \mathrm{~nm}$. The $\mathrm{Ti}+\mathrm{C}$ implantation resulted in a retained dose of approxi-

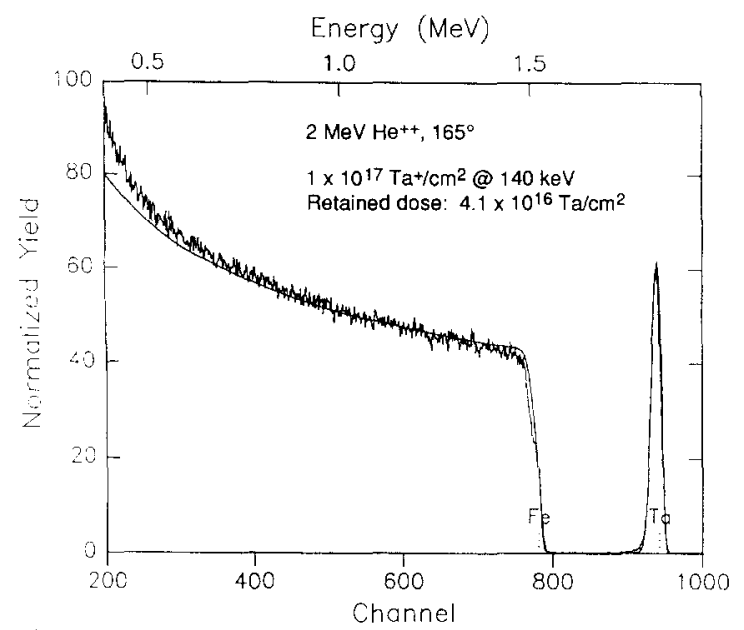

(a)

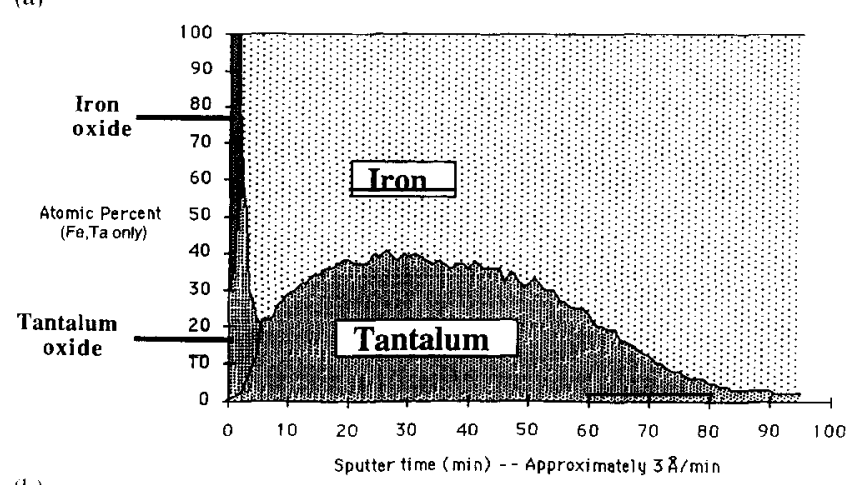

(b)

Fig. 1. RBS spectrum (a) and composition profile as determined by XPS (b) for Ta implanted 52100 steel.

mately $1.7 \times 10^{17} \mathrm{Ti} \mathrm{cm}^{-2}(57 \%$ of nominal) but a much larger amount of $C$, perhaps picked up from the vacuum during deposition. RBS, XPS and PROFILE fitting all agree. The estimated sputtering yields are 2.5 for $\mathrm{Ti}$ and 0.6 for $\mathrm{C}$. A fit to the RBS spectrum using ProfiLE gives a retained dose of $2.2 \times 10^{17} \mathrm{Ti} \mathrm{cm}^{-2}(0.71 \%)$ and an $\mathrm{N}$ dose which appears to be equivalent from XPS analysis. However, the RBS spectrum could only be fitted by assuming a significant concentration of a light element in the surface layers, perhaps $\mathrm{C}$. The lower retained Ti dose (in per cent) in the $\mathrm{Ti}+\mathrm{C}$ implant us. the $\mathrm{Ti}+\mathrm{N}$ implant is expected owing to the lower implantation energy of $\mathrm{Ti}$ in the $\mathrm{T} i+\mathrm{C}$ implantation. Overall, element concentrations and distributions determined using RBS directly, the PROFILE code and XPS agree reasonably well.

\subsection{Corrosion}

Potentiodynamic polarization experiments in $0.5 \mathrm{~N}$ sulfuric acid showed only minor differences in electrochemical behavior between as-received and $(\mathrm{T} i+\mathrm{C}$ or Ta) implanted samples, Fig. 4. Note that the scans are very reproducible and the data on the unimplanted sample agree well with those of Hubler et al. [8] on M50 steel. Hubler showed that Ta implantation results 


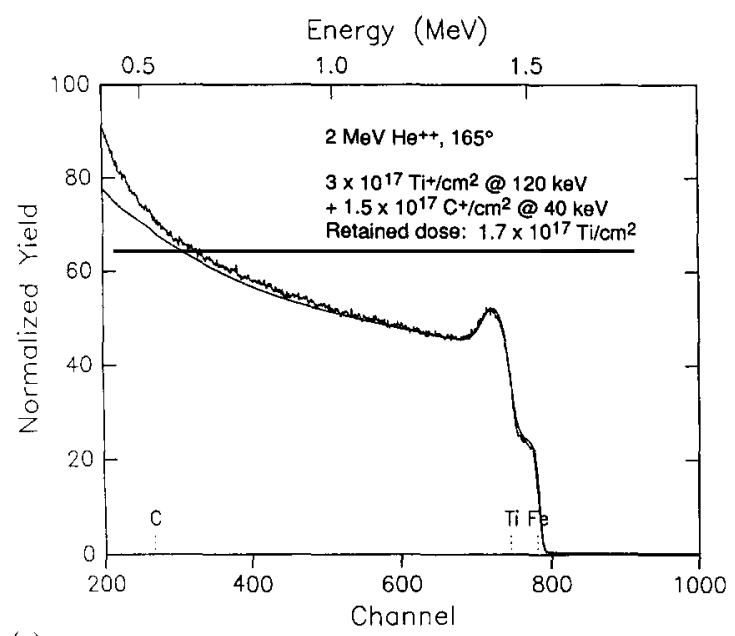

(a)

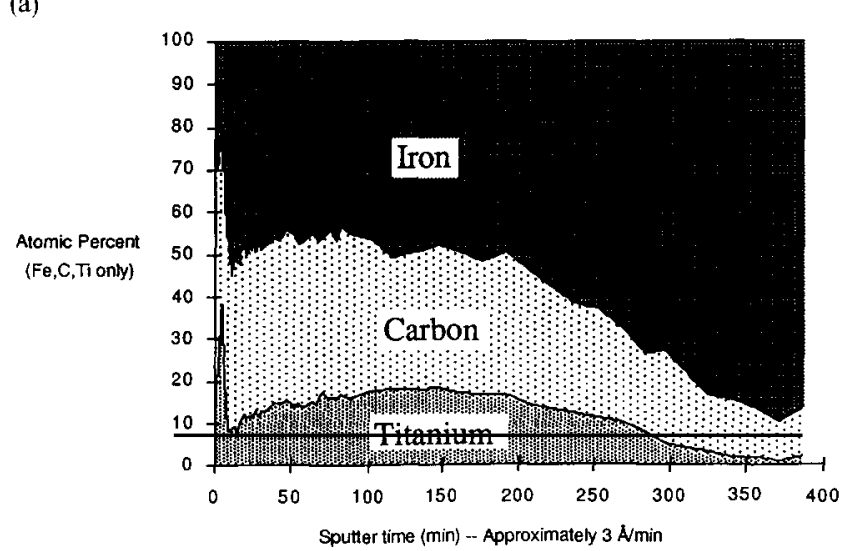

(b)

Fig. 2. RBS spectrum (a) and composition profile as determined by XPS (b) for $\mathrm{Ti}+\mathrm{C}$ implanted 52100 steel.

in a smaller anodic peak and a decrease in the potential at which the current begins to increase in the transpassive region. The same is true of these results but the effect is not as large. Figure 4 shows that both the $\mathrm{Ta}$ and $\mathrm{Ti}+\mathrm{C}$ implanted samples exhibit a lower anodic peak (by about 10 times), an approximately $100 \mathrm{mV}$ drop in the passivation potential and little change in the passive region or the onset of the transpassive region. Analysis of the exposed surfaces indicates that the unimplanted sample corrodes uniformly, resulting in a black corrosion product. However, both the $\mathrm{Ti}+\mathrm{C}$ and $\mathrm{Ta}$ implanted samples retained polishing scratches and were etched in some regions, while others remained reflective. The reduction in the peak anodic current and the decrease in the passivation potential are attributed to the formation of a $\mathrm{Ta}_{2} \mathrm{O}_{5}$ film by selective dissolution of $\mathrm{Fe}$ and reprecipitation of $\mathrm{Ta}$.

Polarization results in $0.1 \mathrm{M}$ buffered $\mathrm{NaCl}$ solution are more striking. The unimplanted samples were severely pitted owing to the low pitting potential $(-100 \mathrm{mV}$ (SCE)), while all implantations were effective in reducing the size of the anodic peak, improving the

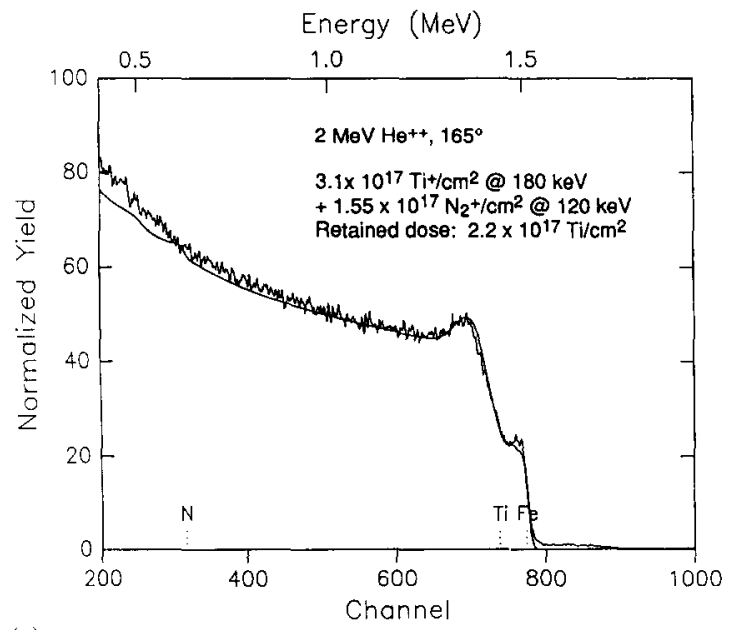

(a)

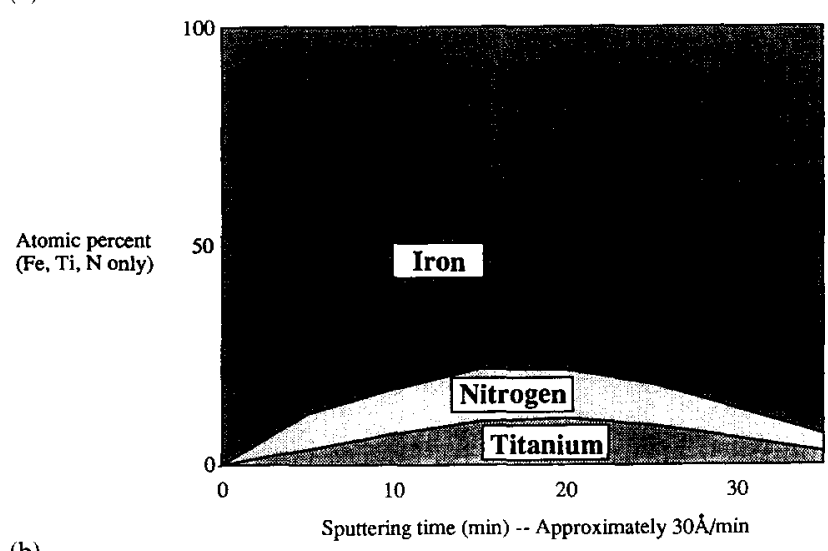

(b)

Fig. 3. RBS spectrum (a) and composition profile as determined by XPS (b) for $\mathrm{Ti}+\mathrm{N}$ implanted 52100 steel.

passivation behavior and raising the pitting potential, Fig. 5. Both $\mathrm{Ta}$ and $\mathrm{Ti}+\mathrm{C}$ implantations increased the open-circuit potential by about $300-350 \mathrm{mV}$, dropped the anodic peak by 100 times and increased the pitting potential by about $1300-1400 \mathrm{mV}$. The Ti+ N implantation did not change the open-circuit potential but decreased the peak anodic current density by more than 100 times and increased the pitting potential by $1400 \mathrm{mV}$. Results for Ta agree extremely well with those of Hubler et al. [8] and Nielsen et al. [10]. Results of $\mathrm{Ti}+\mathrm{C}$ implantation also agree with Hubler et al. [2] and the results of TiN are in line with those observed by others [11]. Pitting was extremely severe in the unimplanted sample, but the sample surface remained bright and free from localized attack in all the implanted surfaces. The one exception was the Ta implantation which showed some pitting, but this may have been due either to the shallow depth of the implant layer relative to the surface roughness or to polarization above the pitting potential. Improved corrosion resistance is attributed to the formation of $\mathrm{Ta}_{2} \mathrm{O}_{5}$ in the case of Ta implantation and perhaps to amorphization of the surface layers. 


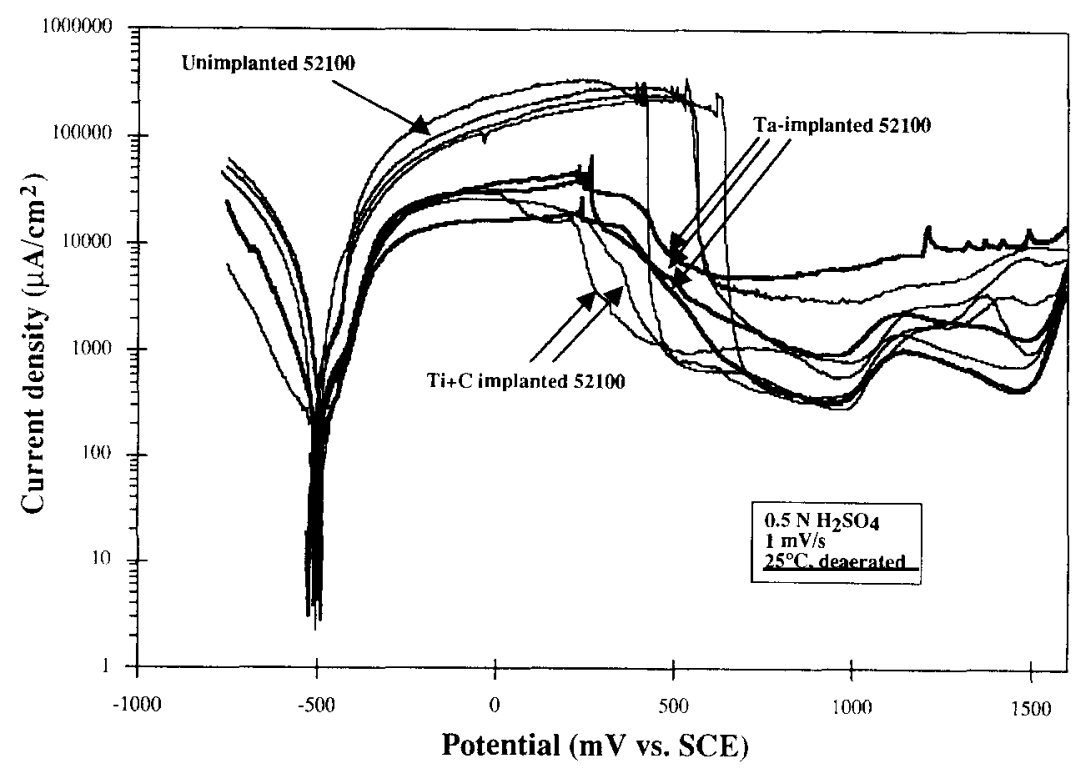

Fig. 4. Potentiodynamic polarization plots of unimplanted. Ta implanted and $\mathrm{Ti}+\mathrm{C}$ implanted 52100 steel in deaerated $0.5 \mathrm{~N}$ sulfuric acid at $25 \mathrm{C}$ and a scan rate of $1 \mathrm{mV} \mathrm{s}^{-1}$.

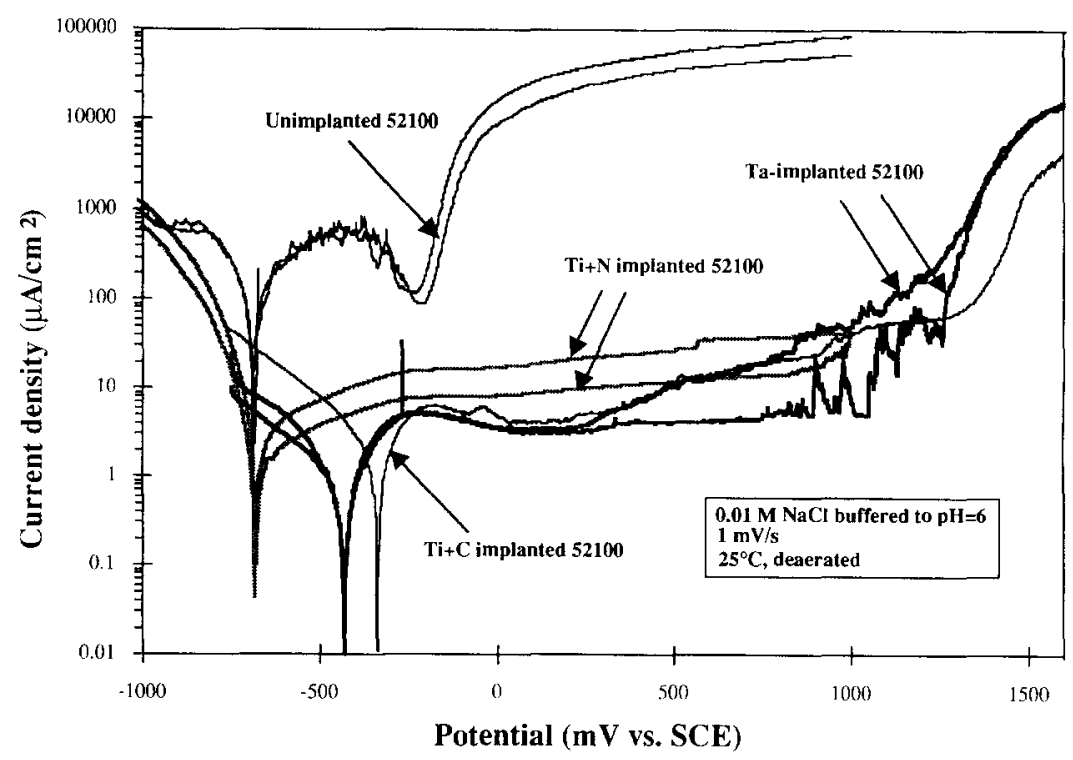

Fig. 5. Potentiodynamic polarization plots of unimplanted. Ta implanted, $\mathrm{Ti}+\mathrm{C}$ implanted and $\mathrm{Ti}+\mathrm{N}$ implanted 52100 steel in deaerated $0.01 \mathrm{M}$ $\mathrm{NaCl}$ buffered to $\mathrm{pH} 6$ at $25 \mathrm{C}$ and a scan rate of $\mathrm{ImV} \mathrm{m}^{-1}$.

\subsection{Wear and hardness}

Scuffing test results are summarized in Fig. 6 which plots the coefficient of friction as a function of the applied load. These results show that both $\mathrm{Ti}+\mathrm{C}$ and $\mathrm{Ti}+\mathrm{N}$ implantation were effective in increasing the loadcarrying capacity over that for unimplanted steel. Ta implantation, however, provided no improvement in the load-bearing capacity, in contrast to the results of Hubler et al. [8]. The load-carrying capacity in the scuffing test is attributed either to the hardness of the surface layer or the change in friction coefficient. This hard, thin layer minimizes plowing and subsurface deformation and hence increases the effectiveness of running-in, thus increasing scuffing resistance. Observed increases in the load-carrying capacity agree fairly well with the measured hardness following implantation, Table 1. Ti+N implantation increases the surface hardness as expected, producing an increase in the scuffing resistance. Both $\mathrm{T} i+\mathrm{C}$ and $\mathrm{Ta}$ implantation, however, reduce the surface hardness, in agreement with Oliver et al. [12]. However, while $\mathrm{Ti}+\mathrm{C}$ was effective in increasing the scuffing resistance, Ta was not. $\mathrm{Ti}+\mathrm{C}$ implantation is known to 


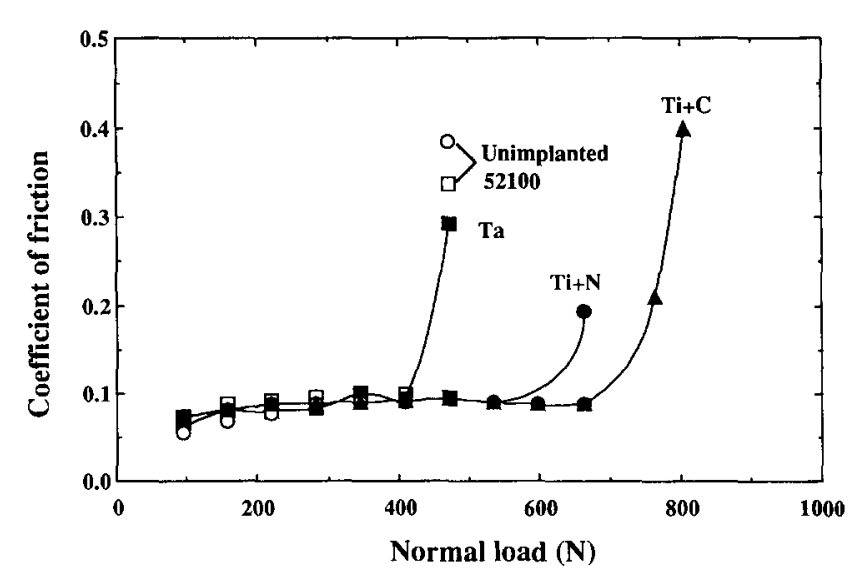

Fig. 6. Coefficient of friction as a function of the normal load in a lubricated step-load test on unimplanted, Ta implanted, $\mathrm{Ti}+\mathrm{C}$ implanted and $\mathrm{T} i+\mathrm{N}$ implanted 52100 steel.

TABLE 1. Normalized hardness of implanted samples

\begin{tabular}{llll}
\hline Load $(\mathrm{g})$ & $\mathrm{Ta}$ & $\mathrm{Ti}+\mathrm{C}$ & $\mathrm{Ti}+\mathrm{N}$ \\
\hline 10 & 0.73 & 0.79 & 0.98 \\
1 & 0.80 & 0.82 & 1.25
\end{tabular}

Hardnesses are relative to the unimplanted values.

reduce the friction coefficient, but no significant change was observed in these tests. Ta implantation is not expected to result in either a harder film or a lower friction coefficient and this is consistent with the observed results.

\subsection{Fretting}

Results of fretting tests are given in Fig. 7. The results are somewhat ambiguous in that there is a large amount of scatter in the data. Inspection of the bearing pattern

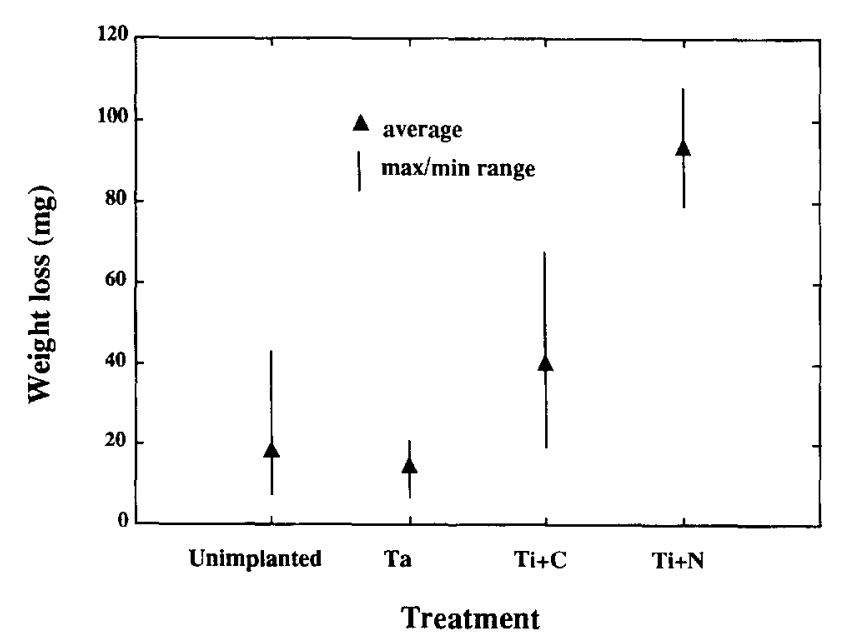

Fig. 7. Weight loss in a fretting test using a Fafnir model 11636 tester and Esso Nebula EP1 batch \#2 grease on unimplanted, Ta implanted, $\mathrm{Ti}+\mathrm{C}$ implanted and $\mathrm{Ti}+\mathrm{N}$ implanted bearings. following testing revealed that misalignment and walking bearings contributed to some of the observed scatter in the data. Walking of bearings affected three of the four unimplanted samples and the other showed indications of load spring misalignment. Walking occurred in both of the $\mathrm{Ti}+\mathrm{N}$ implanted pairs and in one of the four $\mathrm{Ta}$ implanted pairs. There was also some evidence of set screw misalignment in several of the pairs. Although the scatter is great, certain trends can be identified. First, Ta implantation resulted in fretting wear that was on par or slightly improved over the unimplanted bearings. $\mathrm{The} \mathrm{T} i+\mathrm{C}$ implantation resulted in greater fretting wear, as did the $\mathrm{Ti}+\mathrm{N}$ implantation. There appears to be an inverse correlation between fretting wear resistance and surface hardness. This is not totally unexpected. A hard thin layer can be a source of abrasive wear particles in a fretting test. The difference in the role of this layer in sliding wear and fretting wear is the sliding distance. In sliding wear, sliding distances are large and oil constantly sweeps away wear debris before the next pass. However, in the case of fretting caused by high frequency oscillations, the sliding distance is extremely small and wear particles can become trapped between the contact area, acting as hard abrasive particles and promoting fretting wear [13]. The increased hardness of the implanted surface layers may also reduce the fracture resistance, thus increasing the rate of wear particle formation. Finally, oxides which are beneficial in scuffing tests may be detrimental in fretting, as fretting in a nonoxidizing environment has been found to be less severe than in an oxidizing environment [13].

\section{Summary}

The results indicate that all implantations were very effective in improving the corrosion resistance. On average, $\mathrm{T} i+\mathrm{C}, \mathrm{T} i+\mathrm{N}$ and $\mathrm{Ta}$ implantations reduced the peak anodic current by greater than or equal to $300 \mathrm{mV}$, reduced the passivation potential, and increased the pitting potential by over $1000 \mathrm{mV}$. This resulted in the formation of a protective passive film and a high resistance to pitting in both $0.5 \mathrm{M} \mathrm{H}_{2} \mathrm{SO}_{4}$ and $0.1 \mathrm{~N}$ buffered ( $\mathrm{pH}$ 6) $\mathrm{NaCl}$ solutions. $\mathrm{Ti}+\mathrm{C}$ and $\mathrm{Ti}+\mathrm{N}$ implantations significantly increased the wear resistance in a lubricated step-load scuffing test by $60 \%$ and $40 \%$ respectively. Ta produced no improvement in the wear resistance. $\mathrm{Ti}+\mathrm{N}$ implantation increased the hardness by about $25 \%$ and both $\mathrm{Ti}+\mathrm{C}$ and $\mathrm{Ta}$ implantation reduced the surface hardness. Fretting wear was reduced only slightly in the Ta implanted sample and increased in both the $\mathrm{Ti}+\mathrm{C}$ and $\mathrm{Ti}+\mathrm{N}$ implanted samples with the latter showing 4-5 times the weight loss as the unimplanted sample. The fretting results correlate well with hardness, supporting a mechanism in which the 
hard surface layer breaks into fine particles which act as an abrasive under the intense load of the balls. Owing to the very small sliding distance, the wear debris cannot be swept away and ultimately is responsible for the observed weight loss.

\section{Acknowledgments}

The authors gratefully acknowledge the Delco Chassis Division of General Motors Corporation for their financial support. The authors also acknowledge the many helpful discussions with Mr. Ken Neer of Delco Chassis and Dr. Dale Alexander of Argonne National Laboratory and the Michigan Ion Beam Laboratory at the University of Michigan.

\section{References}

1 C. A. Carosella, I. L. Singer, R. C. Bowers and C. R. Gossett. Mater. Sci. Eng., 69 (1985) 103.

2 G. K. Hubler, P. Trzaskoma, E. McCafferty and I. L. Singer, in V. Ashworth, W. A. Grant and R. P. M. Proctor (eds.), Ion Implantation into Metals, Pergamon. New York, 1982, p. 24

3 P. Sioshansi and J. J. Au, Mater. Sci. Eng., 69 (1985) 161.
4 C. R. Clayton, W. K. Chan, J. K. Hirvonen, G. K. Hubler and F. R. Reed, in E. McCafferty, C. R. Clayton and J. Oudar (eds.). Fundamental Aspects of Corrosion Protection by Surface Modification, Electrochemical Society, Pennington, NJ. 1984, p. 17.

5 J. J. O'Connor, in R. B. Waterhouse (ed.). Fretting Fatigue', Applied Science, London, 1981. p. 23.

6 W. C. Oliver, R. Hutchings and J. B. Pethica, Metall Trans. A. 15 (1984) 2221 .

7 V. Ashworth, R. P. Procter and W. A. Grant, The application of ion implantation to aqueous corrosion. In Treatise on Materials Science and Technology, Vol. 18, Academic Press. New York, 1980, p. 175

8 G. K. Hubler, I. L. Singer and C. R. Clayton, Mater. Sci. Eng.. 69 (1985) 203.

9 S. N. Bunker and A. J. Armini, Nucl. Instrum. Methods B, 39 (1989) 7.

10 B. R. Nielsen, B. Torp, C. M. Rangen. M. H. Simplicio. A. C. Colnsiglieri, M. F. DaSilva, F. Paszti, J. C. Soares, A. Dodd, J. Kinder, M. Pitaval. P. Thevenard and R. G. Wing, Nuct. Instrum. Methods B, 59-60)(1991) 772

11 E. I. Meletis, A. Erdimer and R. F. Hochman, in R. F. Hochman (ed.). Ion Plating and Implantation. American Society for Metals. Metals Park, OH, 1986, p. 173

12 W. C. Oliver, R. Hutchings, J. B. Pethica, I. L. Singer and G. K. Hubler, in G. K. Hubler, C. W. White, O. W. Holland and C. R. Clayton (eds.), Ion Implantation and ion Beam Processing of Materials, Materials Research Society Symp. Proc., Vol. 27, Elsevier. New York, 1984, p. 603.

13 J. E. Elder, R. Thamburaj and P. C. Patnaik, Imt. Mater. Re't., 33 (6) (1988) 289 